\title{
The demography and dynamics of an expanding, managed African wild dog metapopulation
}

\author{
Harriet T. Davies-Mostert ${ }^{1,23 *}$, Michael G.L. Mills ${ }^{1,2}$ \& David W. Macdonald ${ }^{1}$ \\ ${ }^{1}$ Wildlife Conservation Research Unit, Recanati-Kaplan Centre, Department of Zoology, Oxford University, \\ Tubney House, Abingdon Road, Tubney, Abingdon OX13 5QL, United Kingdom \\ 2Endangered Wildlife Trust, Private Bag X11, Modderfontein, Johannesburg, 1645 South Africa \\ ${ }^{3}$ Centre for Wildlife Management, University of Pretoria, Pretoria, 0002 South Africa \\ Received 31 August 2014. To authors for revision 15 January 2015. Accepted 30 March 2015
}

\begin{abstract}
Long-term demographic data are central for the evaluation of endangered species recovery plans. We present the demography and dynamics of a managed African wild dog (Lycaon pictus) metapopulation in South Africa, based on life histories of 553 individually known animals collected between 1998 and 2006. This metapopulation, distributed across nine sites (and not including Kruger National Park), was established through reintroductions ( $n=9$ events) and maintained by periodic augmentation ( $n=10$ events) and translocation ( $n=20$ events). In total, 66 founders were used to establish subpopulations and mean founder group size was 9.6 animals. The metapopulation grew from 17 individuals in 1998 to a peak of 202 in 2005. Mean annual population density was 3.3 (S.E. 0.44 ) wild dogs/100 km², approaching the upper limit of densities reported from unmanaged populations. Mean size of breeding packs was 11.0 (S.E. 0.76), comparable to pack sizes in Kruger National Park (Kruger), the only viable unmanaged population in South Africa. Fecundity was lower than in Kruger - particularly in the older age classes. Pup survival to adulthood was $45 \%$ - nearly three times the survival rate for pups in Kruger. Mean annual population growth rate $(\lambda=1.08$, S.E. 0.13) was higher than in unmanaged populations (range 1.000-1.038), with implications for population viability and management.
\end{abstract}

Key words: African wild dogs, demography, dynamics, Lycaon pictus, managed metapopulation, reintroductions, species recovery.

\section{INTRODUCTION}

The African wild dog (Lycaon pictus) has declined over the last century and by 1990 the species was listed as Endangered by IUCN (IUCN, 2009). At that time, its status in South Africa was tenuous, with the Kruger National Park (Kruger) harbouring the only remaining viable population in the country. A Population and Habitat Viability Assessment (PHVA) for wild dogs recommended the expansion of wild dog range in South Africa as an urgent conservation priority (Mills et al., 1998). However, no sufficiently large contiguous patches of suitable habitat existed within which to establish such a population. One solution was to reintroduce wild dogs into the existing network of small, isolated, fenced reserves and parks (Mills et al., 1998).

The establishment of small, isolated populations raised some general concerns. Small populations experience different pressures to large populations: the dynamics of the former are governed by the

*To whom correspondence should be addressed. E-mail: harrietd@ewt.org.za fates of a few individuals and those of the latter by the law of averages (Caughley, 1994). Population persistence is strongly influenced by three types of variability, which all have greater impacts on small populations than large ones. Firstly, small populations are more susceptible to endogenous threats arising from the very nature of being small, including random demographic effects, such as skewed sex ratios, and high or low birth or death rates (Ballou, 1995), which may have disproportionately large effects when populations contain $\geq 25$ individuals (Lande, 1993). Secondly, small populations are vulnerable to genetic stochasticity through increased likelihood of inbreeding and genetic drift due to reduced effective population size (Reed, O'Grady, Ballou \& Frankham, 2003). Finally, exogenous threats include environmental variation, which in extreme cases can lead to catastrophic die-offs (Reed et al., 2003). Environmental variations influence the dynamics of both large and small populations, but small populations may be particularly susceptible and less resilient 
(Reed \& Hobbs, 2004). This is especially true for events such as disease epidemics that may have serious consequences, as has been shown for Ethiopian wolves Canis simensis (Laurenson, Shiferaw \& Sillero-Zubiri, 1997; Marino, SilleroZubiri \& Macdonald, 2006) and wild dogs (Ginsberg, Mace \& Albon, 1995; Hofmeyr, Bingham, Lane, Ide \& Nel, 2000).

In an attempt to circumvent these hazards of small populations, a decision was made to manage the wild dogs in ways that mirror the dynamics of a metapopulation (Mills et al., 1998; Akçakaya, Mills \& Doncaster, 2007). Metapopulations comprise constellations of discrete local breeding subpopulations that display asynchronous dynamics and that are connected through dispersal (Levins, 1969). Metapopulations display more demographic and genetic resilience than single populations particularly when there is gene flow between patches that are susceptible to different environmental variation (Ballou, 1995). Given that most wild dog reintroduction sites would be separated by several hundreds of kilometres, with no guarantee of natural dispersal between them (cf. Somers, Gusset \& Dalerum, 2012), human intervention would be required to ensure gene flow and recolonization of extinct populations (Mills et al., 1998). A series of population viability models (VORTEX; Lacy, 1993) formed the basis of management recommendations to maximize the persistence of the network of reintroduced subpopulations - later known as the managed metapopulation (Davies-Mostert, Mills \& Macdonald, 2009). These models, for which details are provided by Mills et al. (1998), were informed by life history data from long-term studies of unmanaged wild dog populations in Kruger and Moremi Game Reserve, Botswana (Moremi), and assessed founder effects inter alia, the required levels of gene flow (translocations; cf. Gusset et al., 2009) necessary to reduce inbreeding to sustainable levels, and the benefits of disease vaccination programmes. A recovery target was set for at least nine packs in 10 years (Mills et al., 1998).

Nearly a decade after the managed metapopulation strategy was initiated a network of nine small wild dog populations had been established throughout South Africa (Davies-Mostert et al., 2009; Gusset, 2010). These populations were managed collectively with animals periodically transferred between sites to mimic gene flow, and monitoring efforts generated sufficient data to enable an investigation of life-history traits. Given that the managed metapopulation comprised a series of small, discrete populations, each more susceptible than either Kruger or Moremi to threats arising from limited population size, it was anticipated that population dynamics would differ substantially from those used to inform the conservation strategy's development and implementation. Differences in life-history traits such as survival and fecundity might influence population persistence, and the management tools required to maximize it. In this study, our principal objectives were to: determine overall demographic rates for wild dogs within the managed metapopulation; determine those vital rates that had dictated its dynamics between 1998 and 2006; assess the success of the programme in achieving its stated targets; and compare our findings to the demography of larger, unmanaged populations, with special reference to the implications for management. The baseline data originating from this study will facilitate the assessment of long-term persistence of the managed metapopulation, and contribute to effective conservation planning for wild dogs.

\section{STUDY AREA}

The study area encompassed nine reserves participating in the managed wild dog metapopulation programme (Fig. 1). Wild dogs had been previously extirpated from all subpopulation sites prior to initial reintroductions. The reserves ranged in size from 50 to $900 \mathrm{~km}^{2}\left(\right.$ mean \pm S.E. $\left.=437 \pm 93 \mathrm{~km}^{2}\right)$ and were surrounded by electrified perimeter fences. Although all reserves fell within the Savanna Biome (Low \& Robelo, 1996), various vegetation types were represented across the subpopulations (Table 1). All reserves contained populations of preferred wild dog prey, including impala (Aepyceros melampus) and greater kudu (Tragelaphus strepsiceros), but also nyala (Tragelaphus angasi) in KwaZulu-Natal. Populations of key wild dog competitors, namely lions (Panthera leo) and spotted hyaenas (Crocuta crocuta) (Creel \& Creel, 1996; Mills \& Gorman, 1997), were present in all study sites at varying densities. Reserves derived income from various combinations of ecotourism, live game sales and/or hunting, and biodiversity conservation was a primary objective of only two sites.

\section{METHODS}

\section{Monitoring and management}

Population dynamics were tracked in the nine subpopulations between January 1998 and Decem- 


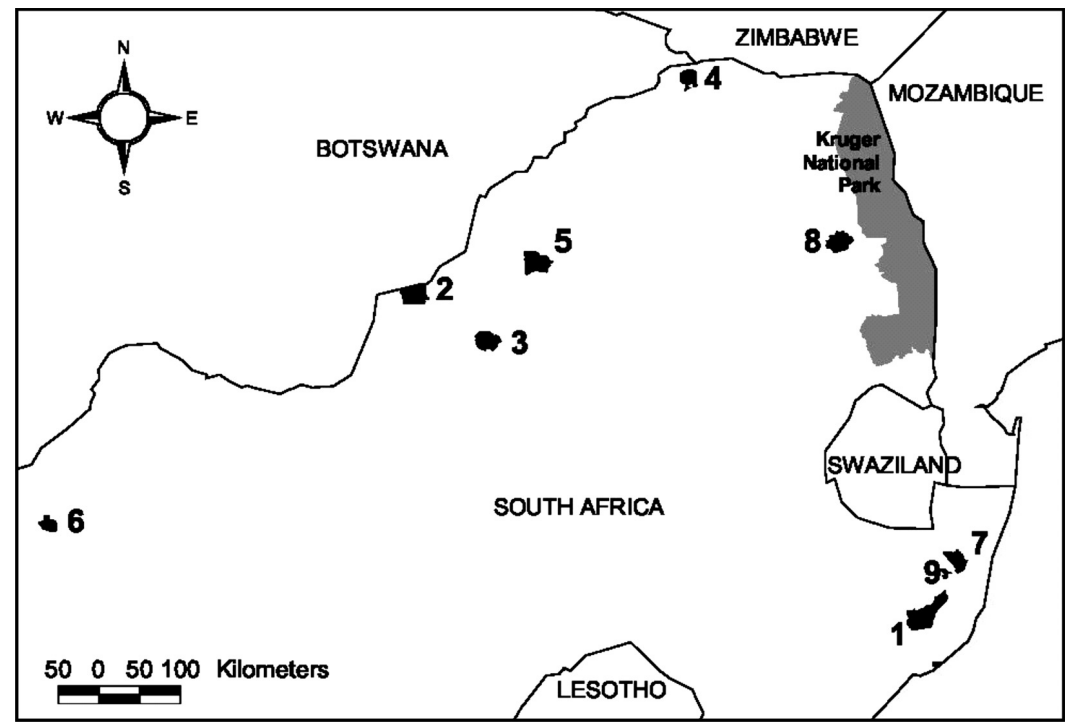

Fig. 1. The location of subpopulations within the managed African wild dog (Lycaon pictus) metapopulation in South Africa (1998-2007). Key: 1, Hluhluwe-iMfolozi Park; 2, Madikwe Game Reserve; 3, Pilanesberg National Park; 4, Venetia Limpopo Nature Reserve; 5, Marakele National Park; 6, Tswalu Kalahari Reserve; 7, Mkhuze Game Reserve; 8, Balule Game Reserve; 9, Thanda Game Reserve.

ber 2006. Reintroductions at two of the reserves had been made before the start of our observations. Wild dogs were first reintroduced into the $900 \mathrm{~km}^{2}$ Hluhluwe-iMfolozi Park (Hluhluwe) in KwaZulu-Natal Province in 1980. By early 1998, this population comprised 12 individuals in three groups, survivors of the earlier reintroductions (Maddock, 1999; Somers, Graf, Szykman, Slotow \& Gusset, 2008). Wild dogs were first reintroduced into the $600 \mathrm{~km}^{2}$ Madikwe Game Reserve (Madikwe) in Northwest Province in 1995. Although the population grew to 24 animals by 1997, only three animals survived a rabies outbreak in early 1998 (Hofmeyr et al., 2000). Between January 1998 and January 2007, seven additional subpopulations were established, encompassing a total area of c. $3930 \mathrm{~km}^{2}$ (Table 1). In chronological order these included Pilanesberg National Park (Pilanesberg), De Beers Venetia Limpopo Nature Reserve (Venetia), Marakele National Park (Marakele), Tswalu Kalahari Reserve (Tswalu), Balule Game Reserve (Balule), Mkhuze Game Reserve (Mkhuze) and Thanda Private Reserve (Thanda).

\section{Population size, structure and density}

Population interventions included reintroductions, defined as the establishment of new subpopulations; augmentations, during which animals new to the metapopulation were added to existing subpopulations; translocations, defined as the movement of animals between subpopulations; and removals, in which animals were permanently extracted from the metapopulation and sent to other conservation areas. Wild dogs were also recaptured as necessary following escapes onto neighbouring land, and these animals were either returned to their source population, translocated elsewhere in the metapopulation or removed entirely. Group size and composition (age and sex) were recorded for all interventions.

Post-release population dynamics were determined from photographic records, radio-telemetry studies and opportunistic sightings (Mills, 1992; Maddock \& Mills, 1994; Somers et al., 2008) (Table 1). Individual life histories were used to document changes in the structure and dynamics of each subpopulation, forming the basis of a database containing a timeline of all known individuals. Date of birth, age and sex were recorded for each individual, as were contemporaneous pack and subpopulation membership. We defined age classes as pups ( $<1$ year), yearlings (1-2 years) and adults ( $>2$ years) (Somers et al., 2008) and recorded the status of each individual on the first day of each month as neonatal, present in group, dispersing, absent or dead. Records only for those wild dogs remaining within the metapopulation were made. Following Creel, Mills \& McNutt (2004), we summa- 
Davies-Mostert et al:: African wild dog metapopulation

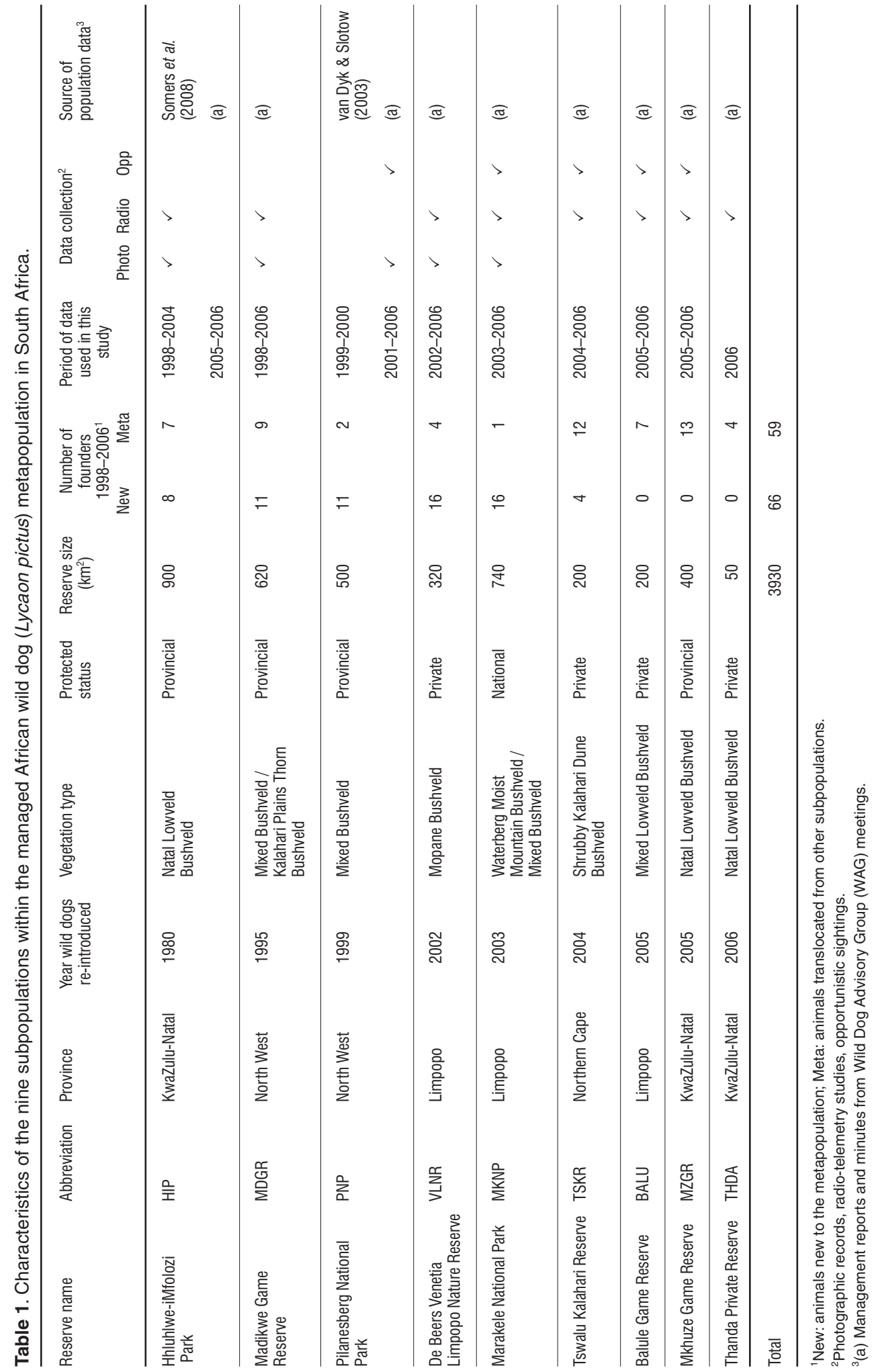


rized subpopulation and metapopulation characteristics on 1 January each year, the mid-point of the wild dog breeding cycle. This provided data on total population size, densities (wild dogs/ $100 \mathrm{~km}^{2}$ ), number of packs (defined as potential breeding units containing at least one unrelated adult pair), number of non-breeding groups, and mean pack and group sizes. We calculated mean annual population growth rate as $\ln \left(n_{t+1} / n_{t}\right)-$ the natural logarithm of the change in the population size $(n)$ from one year $(t)$ to the next $(t+1)-$ correcting population figures for newly reintroduced individuals to avoid inflated annual growth estimates.

We examined population size, growth and density in relation to one another, and to total land area available, which increased with time since metapopulation establishment. The effect of density on metapopulation composition was investigated by plotting densities of individuals and groups against total population size and annual population growth rate.

\section{Breeding and reproduction}

Pregnant females were identified by observation prior to giving birth and post-emergence litter size was determined by counting pups as soon as possible. Although this does not account for preemergence mortality, the constraints on counting pups were similar across subpopulations and enabled comparison of litter size and pup survival across sites and with other studies (Creel et al., 2004; McNutt \& Silk, 2008; Rasmussen, Gusset, Courchamp \& Macdonald, 2008). It was not possible to determine variation in pre-emergence neonatal risks across sites. Pup survival $\left(S_{1}\right)$ was calculated as the number of pups surviving to 12 months of age, as a proportion of $L_{E}$, the litter size at emergence.

We calculated age-specific fecundity $\left(F_{y}\right)$ as $L_{E Y} \times P F_{E} \times P_{y}$ where $L_{E Y}$ was the mean litter size at emergence produced by females of age $y$, $P F_{\mathrm{E}}$ was the proportion of females at emergence across all litters, and $P_{y}$ was the proportion of females of age $y$ that bred.

Sex ratios were determined for each age class (pups, yearlings and adults) on 1 June each year. Sex ratios at birth and 12 months were determined only from litters for which complete sex information was available. Calculations of adult sex ratios ( $\geq 24$ months) included all individuals, as this sex information was complete.
We used Spearman's rank-order correlation coefficient $\left(r_{s}\right)$ to determine the relationships between age of breeding female, parous status, litter size, pack size, number of pups surviving and proportion of pups surviving, unless otherwise indicated. We used two pack size variables to investigate the effect of pack size on pup production and survival: pack size at birth and mean pack size over the year (June-May, following Buettner, Davies-Mostert, du Toit \& Mills, 2007). Parous status was positively correlated to age of breeding female $\left(r_{\mathrm{s}}=0.85, P<0.001, n=45\right.$ litters $)$ and, following McNutt \& Silk (2008), female age was used in subsequent analyses, as it was the easier variable to determine.

\section{Survivorship and mortality}

We calculated age-specific survival for both sexes and overall by determining the proportion of individuals of a given age remaining in each subpopulation from one breeding season to the next, accounting for newly reintroduced animals. Individuals that disappeared from packs and were never detected again were presumed to be dead, or lost to the metapopulation through dispersal.

Apparent adult survival rate (restricted to females) was calculated by determining the proportion of females in each age group that survived from 1 June to the following breeding season. Pup and yearling survival rates were determined for all individuals (i.e. were not restricted to females) in order to reduce the biases described above.

We compared causes of mortality with those in larger, unmanaged wild dog populations, using only mortality data from radio-collared wild dogs to avoid detection biases resulting from differing levels of monitoring intensity (Woodroffe et al., 2007). Pups were never radio-collared, so this approach precluded any comparison of pup mortality. We also examined known causes of mortality for un-collared individuals (adults, yearlings and pups), recognizing that these data cannot be directly compared with other areas without risk of confounding biases.

We recorded the incidence of catastrophic mortality events. These were defined as discrete events that caused mortality of multiple $(>3)$ adults, pups or both, and were important for assessing population viability (Lande, 1993). Although simultaneous death of multiple pups can be common in large populations, we considered this more significant for populations comprising just one or two packs. 


\section{Dispersal}

Wild dogs disperse in same-sex groups of either sex (McNutt, 1996). We identified dispersal events as primary (individuals leaving their natal pack) or secondary (individuals dispersing from non-natal groups), both of which were differentiated from pack fission, which occurred when mixed-sex groups fissured from existing packs to form potential breeding packs containing unrelated individuals of different sexes. Occasionally packs also split into mixed-sex but non-breeding (i.e. related) groups. The timing and group composition of all dispersal events were recorded, as well as whether dispersing groups were tolerated by management within their natal subpopulation, or were translocated elsewhere. Characteristics used elsewhere to describe dispersal - such as dispersal distance (McNutt, 1996), the duration of transience (Maehr, Land, Shindle, Bass \& Hoctor, 2002) or whether new pack formation was achieved successfully (Somers et al., 2008) - were considered irrelevant, as dispersing groups were often used in management interventions, which prevented natural pack formation. Dispersers are often the best choice of dogs for interventions because this mimics the natural state as closely as possible.

\section{Comparison with larger, unmanaged populations}

We compared metapopulation vital rates to those reported for larger, unmanaged populations in order to determine potential effects of intensive management on wild dog demography in small, fenced reserves. Following Creel et al. (2004), we used age-specific survivorship and fecundity to build an age-based Leslie matrix population model for the metapopulation overall, setting age at first parturition at 2 years. The deterministic population growth rate $(\lambda)$ was calculated from the dominant eigenvalue of the Leslie matrix. We validated our parameters by modelling the deterministic population trajectory correcting for newly reintroduced animals and comparing this to census data (Reid, Bignal, Bignal, McCracken \& Monaghan, 2004). We used elasticities to determine which vital rates had the greatest impact on population growth (Caswell, 2001), and compared these to results from the larger, unmanaged wild dog populations examined by Creel et al. (2004), which included the Selous Game Reserve in Tanzania (19911997), Kruger National Park in South Africa (1989-2002) and Moremi Game Reserve and adjacent Wildlife Management Areas in Botswana (1989-2002).

\section{Statistical methods and data sources}

Where sample sizes allowed, spatial and temporal differences in demographic variables were examined by comparing results across subpopulations and years. For the most part, these analyses were only possible for the five reserves that joined the metapopulation prior to 2004. Spearman's rank-order correlation coefficients $\left(r_{\mathrm{s}}\right)$ and partial rank-order correlation coefficients (partial $r_{s}$ ) were used to assess the degree of correlation among variables; other parametric and non-parametric tests (identified in text) were used to compare differences among variables. Such tests do not require that data are distributed normally; however, they do tend to be less sensitive (i.e. have reduced power) at detecting an effect of the independent variable on the dependent variable (Robson, 1994). The relationship between pack size and litter size was determined by regressing pack size at emergence against square-root of litter size for packs where only one female bred and litter size was known $(n=50)$. Leslie matrix calculations and population projections were conducted using the shareware POPTOOLS (Hood, 2006). For all statistical analyses SPSS 14.0 was used.

Metapopulation data were collated from subpopulation managers and researchers (Table 1) and represented all data for the period 1998 to 2007. Comparative data from larger, unmanaged populations were obtained from published literature (Fuller et al., 1992; Creel et al., 2004) and in many cases were derived from study areas comprising just a small proportion of the population. Such data are susceptible to selection biases, as field studies tend to be conducted in areas where study populations are at higher densities (Smallwood \& Schonewald, 1996). As a result, density estimates in these populations are likely to be overestimates for the unmanaged populations they represent. The Kruger data provided an exception as population structure was calculated from photographic submissions from throughout the park, thus providing a minimum count (Maddock \& Mills, 1994).

\section{RESULTS}

\section{Management history}

Sixty-six animals were used as founders in nine separate reintroductions and augmentations between January 1998 and January 2007. These included animals sourced from Kruger (2\%), 
captive stock (15\%), wild-caught packs outside protected areas (58\%) and pups born in holding enclosures while awaiting translocation and/or release $(24 \%)$. Mean founding groups for initial reintroductions were larger than for augmentations, and comprised mostly adults and yearlings, with smaller numbers of pups.

Sixty-nine individuals were used in translocations between reserves, which took place on 20 occasions. These interventions were undertaken to establish new subpopulations $(n=12)$, redress demographic and genetic imbalances at the subpopulation level $(n=4)$, promote new pack formation at release sites $(n=3)$ or remove dispersal groups from areas offering no further breeding opportunities $(n=1)$. Groups were removed from the metapopulation on two occasions: the first when an entire pack was translocated from Pilanesberg to Zimbabwe in an effort to reduce predator pressure in the reserve; the second when a single-sex male group was translocated from Marakele to Kruger in an attempt to prevent inbreeding at Marakele.

\section{Population size, structure and density}

The managed metapopulation was instigated with just 17 individuals in two populations in January 1998 , with the addition of 66 individuals subsequent to 1998. It reached a peak of 202 individuals across all age classes in 16 packs in January 2005 (Fig. 2). At this juncture, densities reached 5.4 wild dogs $/ 100 \mathrm{~km}^{2}$ - nine times higher than concurrent densities in Kruger ( 0.6 wild dogs $/ 100 \mathrm{~km}^{2}$; Kemp \& Mills, 2005). This was mainly a result of the successful breeding season in 2004, when 91 pups were born, of which $82(90.1 \%)$ survived to 1 January 2005. The metapopulation contained

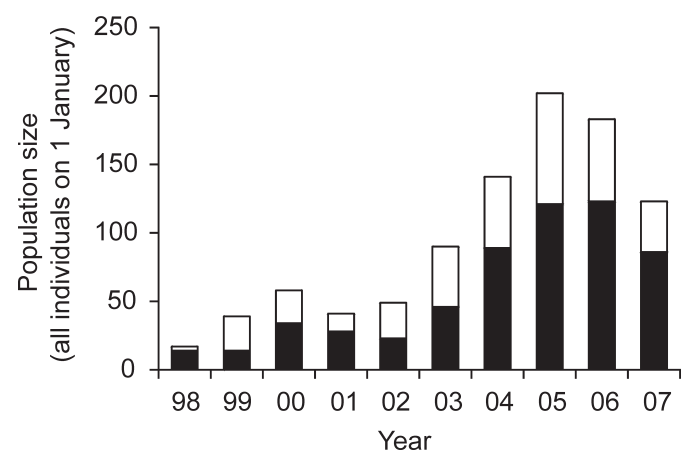

Fig. 2. Number of adult and yearling (black bars) and juvenile (white bars) African wild dogs (Lycaon pictus) in the managed metapopulation in South Africa on 1 January of each year (1998-2007).
143 adults and yearlings at the onset of the 2004 denning season.

Mean annual population density over the complete study interval was 3.3 (S.E. 0.42) wild dogs $/ 100 \mathrm{~km}^{2}$, with an increasing trend over time $\left(r_{\mathrm{s}}=0.77, P=0.009,8\right.$ d.f. $)$ and with the total area under metapopulation management $\left(r_{s}=0.81\right.$, $P=0.005$, 8 d.f.). Mean annual densities for individual reserves were only weakly negatively related to reserve size $\left(r_{\mathrm{s}}=-0.58, P=0.08,8\right.$ d.f. $)$, possibly because small population changes can lead to large density fluctuations in small reserves. Annual densities appeared to be highest at Venetia $\left(6.5\right.$ wild dogs $/ 100 \mathrm{~km}^{2}$ ) but this was not significantly higher than the other three reserves (Hluhluwe, Madikwe and Pilanesberg) where sample sizes were large enough to conduct this comparison (Kruskal-Wallis test; $H_{(4,33)}=7.66, P=$ $0.054,3$ d.f.).

The mean number of groups (breeding and non-breeding) per year was 10.8 (range 5-20, $n=9$ ), and mean group size was 8.7 (S.E. 0.61). When only breeding packs were considered, this rose to 11.0 (S.E. 0.76), which was comparable to mean pack sizes reported for Kruger and northern Botswana (both 10.4), but larger than pack sizes in Selous (8.9; Creel et al., 2004). Mean group size did not increase over time $\left(r_{\mathrm{s}}=0.39, P=0.260, n=\right.$ 9 ), although, as expected, the total number of groups did ( $\left.r_{\mathrm{s}}=0.94, P<0.001, n=9\right)$.

Corrected mean annual population growth rate calculated from life-table analysis was 0.08 (S.E. 0.13, range -0.63-0.53), indicating an average annual population increase of $8 \%$, but with a large $95 \%$ confidence interval $(\mathrm{Cl} 0.25)$. When newly reintroduced animals were included in the calculation of population growth, the figure was 0.22 (S.E. 0.14), indicating that periodic population augmentations may have an important positive effect on population trends (cf. Gusset et al., 2009). After controlling for the size of area available, corrected annual population growth rate was positively correlated with both population size (partial $r_{\mathrm{s}}=0.73, P<0.05, n=9$ ) and density (partial $r_{\mathrm{s}}=0.79, P<0.05, n=9$ ), suggesting an absence of any inverse density-dependent effects on population dynamics, at least over the 9 years covered by this study.

\section{Breeding and reproduction}

The metapopulation contained on average 7.0 (S.E. 1.04, 48\%) breeding females in each breeding season (range 3-11, $n=9$ years) and, as 
Table 2. Litter size, pup survival and yearling survival within the managed African wild dog (Lycaon pictus) metapopulation in South Africa (1998-2006).

\begin{tabular}{|c|c|c|c|c|c|c|}
\hline \multirow[t]{2}{*}{ Subpopulation } & \multicolumn{2}{|c|}{ Litter size $^{1}$} & \multicolumn{2}{|c|}{ Pup survival $\left.\right|^{2,3}$} & \multicolumn{2}{|c|}{ Yearling survival ${ }^{2,3}$} \\
\hline & $n$ & $\begin{array}{l}\text { Mean litter } \\
\text { size } \pm \text { S.E. }\end{array}$ & $n$ & $\begin{array}{l}\text { Mean pup } \\
\text { survival }\end{array}$ & $n$ & $\begin{array}{l}\text { Mean yearling } \\
\text { survival }\end{array}$ \\
\hline Hluhluwe-iMfolozi Park & 18 & $8.3 \pm 0.79$ & 18 & $0.66(0.58-0.74)$ & 17 & $0.67(0.56-0.76)$ \\
\hline Madikwe Game Reserve & 10 & $9.8 \pm 1.04$ & 10 & $0.60(0.50-0.70)$ & 10 & $0.69(0.56-0.80)$ \\
\hline Pilanesberg National Park & 6 & $8.3 \pm 0.56$ & 5 & $0.74(0.61-0.88)$ & 6 & $0.94(0.75-0.98)$ \\
\hline Venetia Limpopo Nature Reserve & 6 & $8.3 \pm 0.71$ & 6 & $0.72(0.58-0.84)$ & 6 & $0.78(0.61-0.90)$ \\
\hline Marakele National Park & 5 & $9.8 \pm 1.59$ & 5 & $0.76(0.61-0.87)$ & 4 & $0.60(0.44-0.75)$ \\
\hline Tswalu Kalahari Reserve & 1 & 4.0 & 1 & 0.00 & 0 & - \\
\hline Balule Game Reserve & 2 & 8.0 & 2 & 0.25 & 0 & - \\
\hline Mkhuze Game Reserve & 2 & 7.0 & 2 & 0.36 & 0 & - \\
\hline Thanda Private Reserve ${ }^{4}$ & - & - & - & - & - & - \\
\hline Managed metapopulation & 50 & $8.6 \pm 0.41$ & 49 & $0.64(0.60-0.69)$ & 43 & $0.71(0.65-0.76)$ \\
\hline
\end{tabular}

${ }^{1}$ Litter sizes are provided only for packs where one female bred.

${ }^{2} \mathrm{Pup}$ and yearling survival rates provided for litters with known fates.

${ }^{3}$ Values in brackets are exact binomial confidence intervals.

${ }^{4}$ No data are available for Thanda as two females bred during the only breeding season within the study period.

expected, the number of breeders increased over time as the number of subpopulations and packs within the metapopulation grew. Mean litter size was 8.6 (S.E. $0.41, n=50$ ) and within the range of mean litter sizes reported elsewhere (Fuller et al., 1992; Creel et al., 2004; McNutt \& Silk, 2008; Rasmussen et al., 2008). Litter sizes did not differ significantly among the five subpopulation reserves (Kruskal-Wallis test: $H_{(4,45)}=1.59, P=0.810$ ), or across the 6 years $\left(2001-2006: H_{(5,43)}=6.4, P=\right.$ $0.269)$ with sample sizes adequate to make this comparison (Table 2).
As has been found in other study sites, pack size at the time of parturition was positively related to the number of pups emerging (linear regression, $\left.F_{(1,56)}=10.54, P=0.002, R^{2}=0.143\right)$, with larger packs producing larger litters (Creel \& Creel, 2002; Buettner et al., 2007; McNutt \& Silk, 2008; Rasmussen et al., 2008). In contrast to results from other populations, there was no relationship between pack size and the proportion of pups surviving to 3, 6 or 9 months (Buettner et al., 2007) or to 1 year (Buettner et al., 2007; McNutt \& Silk, 2008) (Table 3). However, there was a significant

Table 3. Spearman's rank-order correlation coefficients $\left(r_{s}\right)$ for the relationship between pack size at birth and pup survival of African wild dogs (Lycaon pictus) in the managed metapopulation in South Africa, represented as (i) the proportion and (ii) the number of pups surviving to $3,6,9$ and 12 months.

\begin{tabular}{llll}
\hline (i) Proportion ${ }^{1}$ of pups surviving to & $r_{\mathrm{s}}$ & $P$ & $n$ \\
\hline 3 months & 0.263 & 0.068 & 49 \\
6 months & 0.169 & 0.246 & 49 \\
9 months & 0.172 & 0.238 & 49 \\
12 months & 0.155 & 0.293 & $n$ \\
\hline (ii) Number ${ }^{2}$ of pups surviving to & $r_{\mathrm{s}}$ & $P$ & 59 \\
\hline 3 months & 0.309 & 0.017 & 62 \\
6 months & 0.354 & 0.005 & 63 \\
12 months & 0.368 & 0.003 & 6.006 \\
\hline
\end{tabular}

${ }^{1}$ Includes only those litters that can be ascribed to one female, and have known fates.

${ }^{2}$ Includes all litters with known fates. 
positive relationship between pack size and the actual number of pups surviving to these ages (Table 3), with the result that larger packs produced a larger number of yearling recruits than did smaller packs. This mirrors the direction of the non-significant relationship found by Gusset \& Macdonald (2010).

Fecundity increased with age, with older females producing significantly more offspring than did younger females (Kruskal-Wallis test, $H_{(5,50)}=$ 20.76, $P=0.001$ ), and a larger proportion of older female age classes breeding (chi-square test, $\chi^{2}=68.4, P<0.001,5$ d.f.). No data were available for females $>9$ years old.

Sex ratio of pups at emergence was biased towards males ( 80 of 136 pups $=0.59$; exact binomial test; $P=0.048$, for litters where sex information was complete). The proportion of males was not related to the age of the breeding female $\left(r_{\mathrm{s}}=0.08, P=0.75, n=19\right)$ or litter size $\left(r_{\mathrm{s}}=0.10\right.$, $P=0.68, n=19)$ as suggested in earlier studies (Fuller et al., 1992). The male-skewed sex ratios were equally apparent for yearlings $(0.58$; exact binomial test; $P=0.01, n=220)$ and adults $(0.56$; exact binomial test; $P<0.01, n=569$ ), concordant with results of other studies (Fuller et al., 1992).

\section{Survivorship and mortality}

Age-specific annual survival rates for females are provided in Fig. 3. In total, $45 \%$ of pups born into the metapopulation survived to adulthood (2 years). Adult survival was highest for 2-yearolds (0.91, exact binomial $\mathrm{Cl} 0.82-0.96$ ), with no significant trend towards decreasing survival rates with senescence $\left(r_{\mathrm{s}}=-0.08, P=0.844, n=\right.$ $8)$. Variance in survival rates was largest for the oldest age classes, as estimates were derived from increasingly fewer individuals. Male survival tended to be higher than female survival for all age classes, although this was not significant (MannWhitney, $U$-test; $U=82.5, P=0.139, n=8$ ).

The age-based Leslie matrix for females within the managed metapopulation was constructed as follows:

\begin{tabular}{|l|l|l|l|l|l|l|l|l|}
\hline & 0.00 & 0.00 & 0.09 & 0.58 & 1.43 & 2.08 & 3.00 & 2.73 \\
\hline & 0.64 & 0.00 & 0.00 & 0.00 & 0.00 & 0.00 & 0.00 & 0.00 \\
\hline & 0.00 & 0.71 & 0.00 & 0.00 & 0.00 & 0.00 & 0.00 & 0.00 \\
\hline$A=$ & 0.00 & 0.00 & 0.91 & 0.00 & 0.00 & 0.00 & 0.00 & 0.00 \\
\hline & 0.00 & 0.00 & 0.00 & 0.64 & 0.00 & 0.00 & 0.00 & 0.00 \\
\hline & 0.00 & 0.00 & 0.00 & 0.00 & 0.61 & 0.00 & 0.00 & 0.00 \\
\hline & 0.00 & 0.00 & 0.00 & 0.00 & 0.00 & 0.67 & 0.00 & 0.00 \\
\hline & 0.00 & 0.00 & 0.00 & 0.00 & 0.00 & 0.00 & 0.63 & 0.57 \\
\hline
\end{tabular}

where the first row represents age-specific fecundity of females aged $0-8$ years, and the diagonal represents annual survival rates for each age class. Annual population growth rate calculated from the dominant eigenvalue of the Leslie matrix $(\lambda=1.10)$ was higher than, but fell within the $95 \%$ confidence interval around the annual population growth rate calculated from corrected population figures using established methods $(\lambda=1.08)$. Deterministic population projections from the Leslie matrix corresponded to observed population sizes. Inter-annual variation in metapopulation growth rate was high, and 95\% confidence intervals enclosed the value of $r=0$, suggesting that metapopulation growth was unstable, with

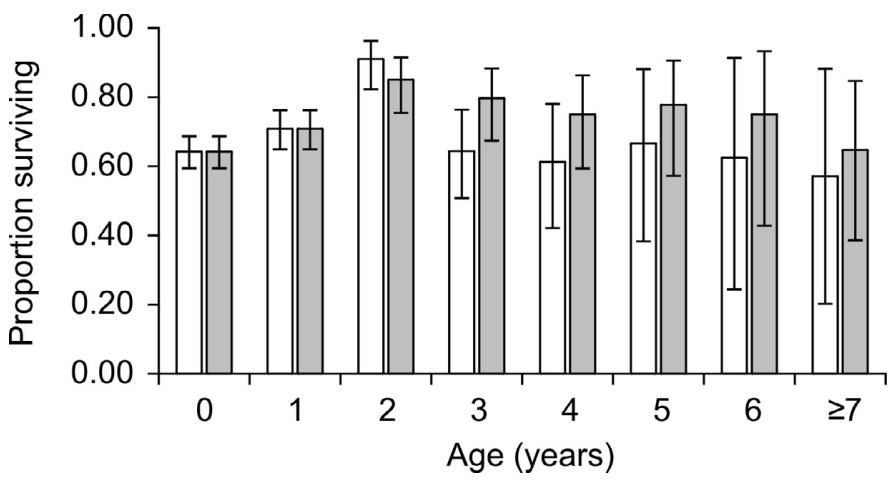

Fig. 3. Age-specific annual survival rates for female (white bars) and male (grey bars) African wild dogs (Lycaon pictus) in the managed metapopulation in South Africa. Data are pooled for animals $\geq 7$ years to maintain sample sizes. Error bars show exact binomial confidence intervals. 
potentially large fluctuations between positive and negative growth, typical of wild dog populations elsewhere (Creel et al., 2004).

The elasticity of $\lambda$ to changes in age-specific survival and fecundity did not differ significantly between the metapopulation and Kruger $(U=$ 89.5, $P=0.75$ and $U=86.0, P=1.00, n=9$, respectively; Fig. 4) - with survival of the youngest age classes having the largest effect on population growth rate (Creel et al., 2004). This was despite apparent differences in fecundity and survivorship between the two populations.

Causes of mortality could be assigned to the categories defined by Woodroffe et al. (2007), with the exception that animals within the metapopulation were also vulnerable to mortality arising from management interventions - primarily immobilization and capture (Table 4). As in Kruger, natural mortality was the most important cause of death among collared individuals. Pups in the metapopulation appeared more vulnerable to human-induced mortality (46\% vs $1 \%$; chi-square goodness of fit, $\chi^{2}=40.7, P<0.001,2$ d.f. $)$ - most of which arose from unsuccessful relocations during the denning season.

Catastrophic events (at the subpopulation level) took place only occasionally and were related to

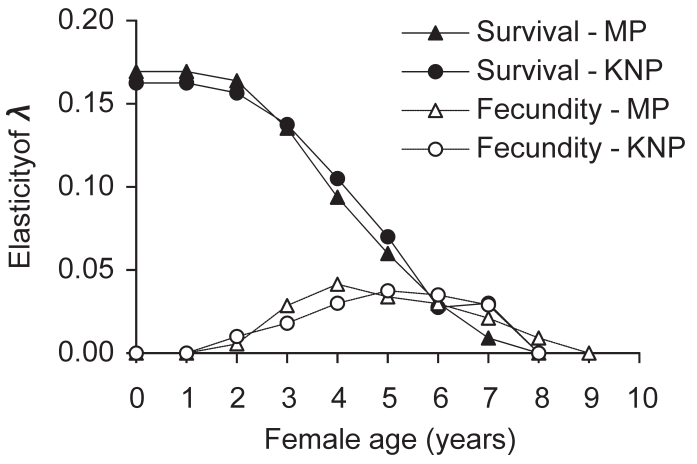

Fig. 4. Elasticity of population growth rate (III) of African wild dogs (Lycaon pictus) to changes in age-specific female survivorship and fecundity in the managed metapopulation (MP) in South Africa, as compared to the unmanaged population in Kruger National Park (KNP). Population growth rates for both MP and KNP respond most strongly to changes in pup and yearling survival. The distribution of elasticities for fecundity and survival do not differ between the two populations (Mann Whitney $U$-tests: $W=89.5, P=0.75$ and $W=86.0, P=1.00, n=9$, respectively).

disease (Madikwe 2000, Tswalu 2005), human conflict (Marakele 2004, Venetia 2005, Balule 2006) or factors affecting pack viability (Venetia 2005). Only one case of subpopulation extinction

Table 4. Causes of African wild dog (Lycaon pictus) mortality within the managed metapopulation (MP) in South Africa, as compared to the unmanaged population in Kruger National Park (KNP; data from Woodroffe et al., 2004).

\begin{tabular}{|c|c|c|c|c|c|c|}
\hline \multirow[t]{2}{*}{ Known causes of mortality } & \multicolumn{2}{|c|}{$\begin{array}{l}\text { Radio-collared } \\
\text { individuals }\end{array}$} & \multicolumn{2}{|c|}{$\begin{array}{l}\text { Identified adults } \\
\text { and yearlings }\end{array}$} & \multicolumn{2}{|c|}{ Pups } \\
\hline & $\begin{array}{c}\text { MP } \\
n=21\end{array}$ & $\begin{array}{c}\mathrm{KNP} \\
n=15\end{array}$ & $\begin{array}{c}\text { MP } \\
n=44\end{array}$ & $\begin{array}{c}\text { KNP } \\
n=11\end{array}$ & $\begin{array}{c}\mathrm{MP} \\
n=46\end{array}$ & $\begin{array}{c}\mathrm{KNP} \\
n=68\end{array}$ \\
\hline \multicolumn{7}{|l|}{ Natural causes } \\
\hline Natural injury or accident & $14 \%$ & $0 \%$ & $11 \%$ & $18 \%$ & $2 \%$ & $3 \%$ \\
\hline Starvation & $0 \%$ & $0 \%$ & $0 \%$ & $0 \%$ & $0 \%$ & $0 \%$ \\
\hline Old age & $0 \%$ & $0 \%$ & $0 \%$ & $0 \%$ & $0 \%$ & $0 \%$ \\
\hline Other wild dogs & $24 \%$ & $33 \%$ & $20 \%$ & $27 \%$ & $2 \%$ & $25 \%$ \\
\hline Predator & $33 \%$ & $27 \%$ & $14 \%$ & $18 \%$ & $13 \%$ & $35 \%$ \\
\hline Subtotal & $71 \%$ & $60 \%$ & $45 \%$ & $64 \%$ & $17 \%$ & $63 \%$ \\
\hline \multicolumn{7}{|l|}{ Human causes } \\
\hline Road/train accident & $0 \%$ & $7 \%$ & $9 \%$ & $0 \%$ & $4 \%$ & $0 \%$ \\
\hline Shot/speared & $5 \%$ & $27 \%$ & $18 \%$ & $0 \%$ & $0 \%$ & $0 \%$ \\
\hline Poisoned & $5 \%$ & $0 \%$ & $0 \%$ & $0 \%$ & $0 \%$ & $0 \%$ \\
\hline Snared & $10 \%$ & $0 \%$ & $7 \%$ & $36 \%$ & $7 \%$ & $1 \%$ \\
\hline Management intervention & $5 \%$ & $0 \%$ & $9 \%$ & $0 \%$ & $35 \%$ & $0 \%$ \\
\hline Subtotal & $24 \%$ & $33 \%$ & $43 \%$ & $36 \%$ & $46 \%$ & $1 \%$ \\
\hline Disease & $5 \%$ & $7 \%$ & $11 \%$ & $0 \%$ & $37 \%$ & $35 \%$ \\
\hline Subtotal & $5 \%$ & $7 \%$ & $11 \%$ & $0 \%$ & $37 \%$ & $35 \%$ \\
\hline Total & $100 \%$ & $100 \%$ & $100 \%$ & $100 \%$ & $100 \%$ & $100 \%$ \\
\hline
\end{tabular}


Table 5. Summary dispersal statistics for African wild dogs (Lycaon pictus) in the managed metapopulation in South Africa (1998-2006).

\begin{tabular}{|c|c|c|c|c|c|}
\hline \multirow[t]{2}{*}{ Variable } & & \multicolumn{3}{|c|}{ Sex } & \multirow[t]{2}{*}{ All } \\
\hline & & Males & Females & Mixed & \\
\hline Number of dispersal events (groups) & $\begin{array}{l}\text { Primary } \\
\text { Secondary }\end{array}$ & $\begin{array}{c}20 \\
4\end{array}$ & $\begin{array}{c}16 \\
3\end{array}$ & 1 & $\begin{array}{c}37 \\
7\end{array}$ \\
\hline Number of individuals dispersing & $\begin{array}{l}\text { Primary } \\
\text { Secondary }\end{array}$ & $\begin{array}{c}59 \\
5\end{array}$ & $\begin{array}{c}56 \\
4\end{array}$ & & $\begin{array}{c}115 \\
9\end{array}$ \\
\hline Mean size of dispersing groups ( \pm S.E.) & $\begin{array}{l}\text { Primary } \\
\text { Secondary }\end{array}$ & $\begin{array}{l}2.9 \pm 0.37 \\
1.3 \pm 0.25\end{array}$ & $\begin{array}{l}3.4 \pm 0.48 \\
1.3 \pm 0.33\end{array}$ & 4.0 & $\begin{array}{l}3.1 \pm 0.29 \\
1.3 \pm 0.18\end{array}$ \\
\hline Median age (months) at dispersal (range) & $\begin{array}{l}\text { Primary } \\
\text { Secondary }\end{array}$ & $\begin{array}{c}26.5(8.5-62.5) \\
43.5(33.0-53.5)\end{array}$ & $\begin{array}{l}21.0(13.5-62.2) \\
36.5(36.5-56.5)\end{array}$ & $38.5(33.0-56.5)$ & $25.0(8.5-62.5)$ \\
\hline Dispersals out of source subpopulations & $\begin{array}{l}\text { Events } \\
\text { Individuals }\end{array}$ & $\begin{array}{c}7 \\
25\end{array}$ & $\begin{array}{c}6 \\
30\end{array}$ & 1 & $\begin{array}{l}14 \\
55\end{array}$ \\
\hline $\begin{array}{l}\text { Number of individuals permanently } \\
\text { leaving the metapopulation }\end{array}$ & $\begin{array}{l}\text { Primary } \\
\text { Secondary }\end{array}$ & $\begin{array}{c}19 \\
1\end{array}$ & $\begin{array}{c}20 \\
1\end{array}$ & & $\begin{array}{c}39 \\
2\end{array}$ \\
\hline $\begin{array}{l}\text { Mean annual \% of adults and yearlings } \\
\text { emigrating }\end{array}$ & & $5.3 \%$ & $7.8 \%$ & & $6.3 \%$ \\
\hline
\end{tabular}

was recorded, this following an outbreak of canine distemper at Tswalu in 2005, during which four adults and five juveniles died. Population augmentations staved off extinctions elsewhere.

\section{Dispersal}

Thirty-seven incidents of primary dispersal were recorded between 1998 and 2006, involving 115 animals (Table 5). Male and female dispersing groups were of similar size (2.9 males (S.E. 0.37) vs 3.4 females (S.E. 0.48), Mann-Whitney $\left.U=182.5, z=-0.7, P=0.484, n_{1}=20, n_{2}=16\right)$, and females were younger than males when they first left natal packs (median, 21.0 vs 26.5 months, $\left.U=1097.5, z=3.1, P=0.002, n_{1}=59, n_{2}=56\right)$. One case of primary dispersal involved a mixedsex group of four animals (two males, two females), although this group split by sex two weeks later. The annual incidence of primary dispersal was positively correlated with the number of breeding packs $\left(r_{\mathrm{s}}=0.78, P<0.05, n=8\right)$ and wild dog density $\left(r_{\mathrm{s}}=0.95, P<0.05, n=8\right)$ on 1 January each year (Table 5). However, per capita annual incidence of primary dispersal was not correlated to either wild dog density $\left(r_{\mathrm{s}}=0.43, P>0.5, n=8\right)$ or the number of breeding packs $\left(r_{\mathrm{s}}=0.19\right.$, $P>0.05, n=8$ ), suggesting an absence of any density effects on primary dispersal rates. Secondary dispersal was recorded in Hluhluwe $(n=4)$, Pilanesberg $(n=2)$ and Marakele $(n=1)$ (Table 5).

Dispersing groups were observed with unrelated animals of the opposite sex in 29 (76\%) of 38 primary and secondary dispersal events for which the outcome was known. Animals were also captured and introduced to artificially establish new packs either at the source site $(n=1)$ or at other metapopulation sites $(n=5)$. At least 41 individuals were confirmed to have naturally emigrated from the metapopulation, while another 27 individuals were removed to sites outside the metapopulation.

\section{DISCUSSION}

Understanding the influence of life-history traits on population regulation is especially important for managed populations, in which there is scope to target specific interventions to improve or stabilize population growth. The process of establishing a managed wild dog metapopulation in South Africa enabled the collection of demographic and lifehistory data over 9 years while the population was expanding. Several long-term studies of wild dog population dynamics in large unmanaged systems such as the Serengeti (Fuller et al., 1992), Kruger (Maddock \& Mills, 1994; Buettner et al., 2007), Selous (Creel \& Creel, 2002) and northern Botswana (Creel et al., 2004; McNutt \& Silk, 2008), provided a benchmark for the operation of natural wild dog population dynamics, and a means to assess whether various life-history traits in the managed metapopulation fell within the parameters of 'natural' populations. We observed broadly 
similar traits to those in larger populations, suggesting that natural population dynamics can be achieved even in systems that are intensively managed. However, this study metapopulation displayed population densities, pup and yearling survival rates, as well as annual population growth rates higher than those recorded in established and unmanaged populations. Elevated rates could be attributed to the fact that subpopulations were being established in unoccupied areas with low levels of intra-specific competition, as has been found for other recolonizing carnivore populations (Pletscher, Ream, Boyd, Fairchild \& Kunkel, 1997; Bales, Hellgren, Leslie \& Hemphill, 2005).

\section{Elevated population densities}

Wild dog densities are low when compared to those of most other large predators (Creel \& Creel, 1996) and are negatively correlated with lion densities in a range of ecosystems (Mills \& Biggs, 1993; Creel \& Creel, 1996, 1998, 2002). Wild dogs are able to coexist with these larger predators by avoiding them both spatially (Mills \& Gorman, 1997; Creel \& Creel, 2002) and temporally (Saleni et al., 2007). Lion-induced mortality has hampered at least one previous wild dog reintroduction (Scheepers \& Venzke, 1995) and has been flagged as a factor likely to limit reintroduction success (Mills et al., 1998). Although we recorded lioninduced mortality in our study (Table 4), this was not, as would be expected, at a rate high enough to affect successful establishment of populations (Gusset et al., 2008; Gusset, Stewart, Bowler \& Pullin, 2010).

Wild dog densities were consistently higher than in Kruger and tended to be higher than in most of the other large unmanaged conservation areas, notwithstanding that high metapopulation densities were partially offset by the periodic addition of habitat in the form of new subpopulation sites. Mean pack sizes were comparable to those in unmanaged populations (Fuller et al., 1992; Creel et al., 2004) and it follows that the higher individual densities (i.e. wild dogs $/ 100 \mathrm{~km}^{2}$ ) were a result of higher pack densities (i.e. packs $/ 100 \mathrm{~km}^{2}$ ). Annual wild dog ranges have been reported to overlap only by $30-35 \%$ in Kruger (Reich, 1981) and between $10-50 \%$ in the Serengeti (Frame \& Frame, 1976), thus higher pack densities were probably a consequence of an increase in range overlap within metapopulation reserves, a reduction in pack home range sizes, or both.

Carnivore ranging behaviour is influenced by various factors including the ability to meet their ecological requirements (food acquisition, avoidance of predation) and also their social requirements (territoriality, mating). Elevated wild dog densities in the metapopulation suggest that packs were able to meet these requirements in smaller areas - at least during the period covered by this study - and that their home ranges were somehow constrained, either by perimeter fences or because release sites were resource-rich. There is evidence that wild dog hunting success in small fenced areas is improved by the propensity of wild dogs to capture prey against perimeter fences (Van Dyk \& Slotow, 2003; Rhodes \& Rhodes, 2004; Davies-Mostert, Mills \& Macdonald, 2013). Prey availability might also have temporarily increased following herbivore reintroductions at some subpopulation sites. This would have increased densities and also provided naïve prey individuals that were more susceptible to predation (H.T. Davies-Mostert, unpubl. data 2010).

An alternative explanation for elevated wild dog densities is the statistical artefact of reintroducing wild dogs into areas smaller than their natural home range sizes. Only three of the nine subpopulation sites were larger than the average range of wild dog packs in Kruger (537 km² ; Mills \& Gorman, 1997) and four were actually smaller than the minimum range size reported $\left(357 \mathrm{~km}^{2}\right.$; Mills \& Gorman, 1997). A breeding pair of wild dogs - the minimum required to meet the definition of a pack - in a $50 \mathrm{~km}^{2}$ reserve (the size of Thanda, the smallest subpopulation site) equates to a density of 4.0 wild dogs $/ 100 \mathrm{~km}^{2}$. This is twice the density of wild dogs in Kruger when the population reached its peak in 1995, and does not account for any population growth following successful breeding. We suggest that elevated wild dog densities in the metapopulation can be at least partially explained by the fact that populations are constrained by electrified fences, which impede (but do not completely prevent; see Davies-Mostert et al., 2012, 2013) dispersing individuals from moving out of their natal ranges. Elevated wild dog densities have created challenges in some subpopulation reserves due to the perception that they increase predation pressure on herbivore populations (Davies-Mostert et al., 2009). Although a deeper understanding of the sustainability of predation will be useful for the future management of large carnivores in small areas (e.g. cheetahs (Acinonyx jubatus) and lions in South Africa), most reserves are unwilling to allow predation to con- 
(i)

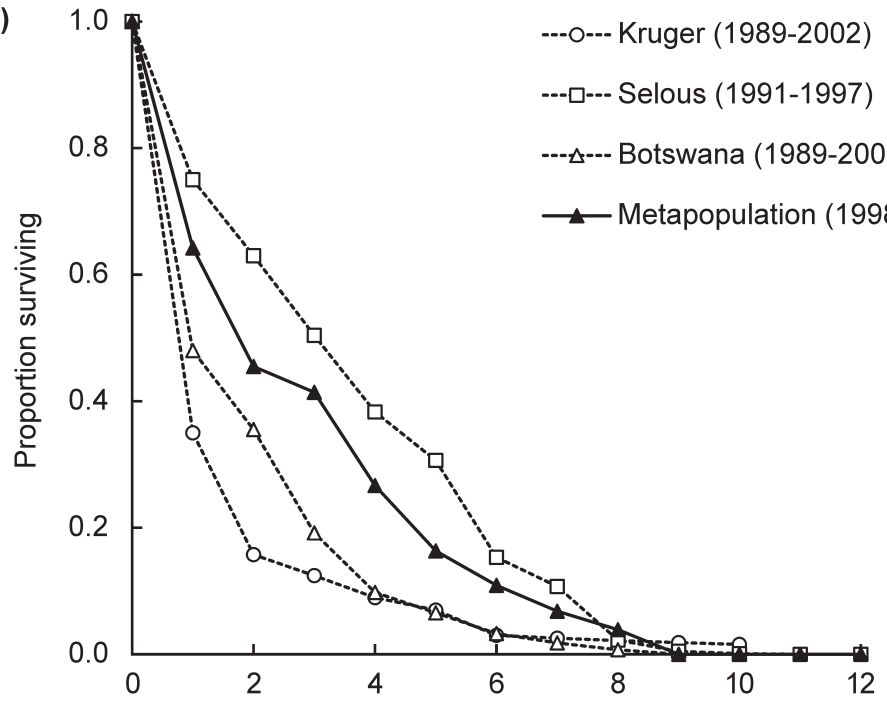

(ii)

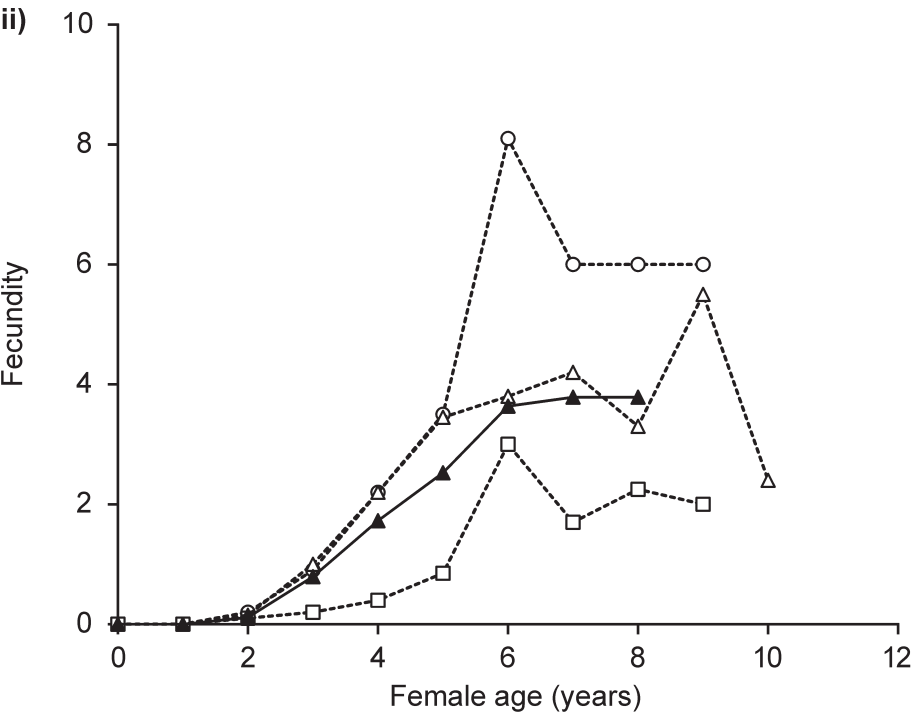

Fig. 5. Comparison of (i) female survivorship and (ii) age-specific fecundity in the managed metapopulation of African wild dogs (Lycaon pictus) in South Africa with those of unmanaged populations (Kruger National, Selous Game Reserve and northern Botswana; data from Creel et al., 2004). Fecundity is measured as litter size divided by two, and age-specific fecundity incorporates the proportion of females breeding in each age class. Fecundity data for the metapopulation and Kruger were pooled across females $\geq 7$ years to maintain sample sizes.

tinue unchecked and future field trials to investigate density dependence seem highly unlikely.

\section{Elevated pup and yearling survival}

It has been established that there are trade-offs between life-history traits within wild dog populations, with litter sizes being offset by pup survival, reproduction by adult survival, and juvenile survival rates offset by those of adults (Fuller et al., 1992; Creel et al., 2004; Gusset \& Macdonald, 2010).
Survival rates for pups and yearlings in the metapopulation were higher than for both Kruger and northern Botswana (Fig. 5). This is important, firstly because survival of pups and yearlings has the largest effect on population growth (Creel et al., 2004; this study), and secondly because litter sizes in the metapopulation are not smaller than in unmanaged populations. Consequently, population growth in the managed metapopulation was considerably higher than for the unmanaged pop- 
ulations investigated by Creel et al. (2004), for which values of $\lambda$ ranged from 1.000 (northern Botswana) to 1.038 (Selous). However, the annual metapopulation growth rate was highly variable, and $95 \%$ confidence intervals enclosed the value of $r=0$, suggesting that metapopulation growth was unstable, with the potential for large fluctuations between positive and negative growth. This is a characteristic of wild dog populations generally.

\section{Other factors influencing survival and population viability}

Causes of adult wild dog mortality were similar to those in unmanaged populations, but pup mortality attributed to human causes was much higher. While recognizing that mortality data for pups are inherently biased (Woodroffe et al., 2007), most pup mortality was attributed to management interventions and probably reflects true differences between managed and unmanaged populations. Anthropogenic mortality of wild dogs tends to be additive to natural causes (Woodroffe et al., 2007) and hence efforts to reduce management-induced pup mortality would be likely to result in an improvement in overall pup survival. This, in turn, would create an even larger discrepancy in survival rates between the metapopulation and unmanaged populations.

Catastrophic events such as those caused by disease or human persecution can have significant impacts on tiny wild dog populations (Ginsberg et al., 1995; Ginsberg \& Woodroffe, 1997; Hofmeyr et al., 2000; Hofmeyr, Hofmeyr, Nel \& Bingham, 2004). Although catastrophic disease outbreaks (canine distemper) led to the extinction of one subpopulation during the period covered by this study (Tswalu 2005), this represented just 3.6\% and $4.9 \%$ of adults and pups in the metapopulation, respectively. After 2004, no subpopulation comprised more than $38 \%$ of the total metapopulation; therefore, even though small populations are more susceptible to catastrophic events, catastrophic mortality at the subpopulation level was unlikely to have major impacts at the metapopulation level (cf. Gusset et al., 2008, 2010). This is one of the benefits of spreading risk across several isolated populations (Shafer, 2001).

\section{Outlook for conservation management of large carnivores}

The dynamics exhibited by this managed wild dog metapopulation were indicative of an expand- ing population as packs were established in areas free from conspecifics. Although metapopulation dynamics were in part an artefact of direct management intervention, the high population growth rates we observed demonstrated that wild dogs were able to successfully re-colonize new areas given suitable habitat and prey base, and adequate protection from human conflict (Gusset, 2009). Similar successes have been described for other large-carnivore recovery programmes (lions, Hunter et al., 2007; wolves (Canis lupus), White, Lemke, Tyers \& Fuller, 2008; cheetahs, Marnewick, Hayward, Cilliers \& Somers, 2009) and although this bodes well for reintroductions, high population growth rates can also contribute to the complexities of population management (DaviesMostert et al., 2009). This is particularly relevant in small, fenced reserves where there is little opportunity for population expansion. Continued fragmentation of landscapes is likely to necessitate the managed metapopulation approach to conserving wide-ranging animals and our study emphasizes the importance of protected areas (even relatively small ones) for the conservation of carnivores as an alternative to the very difficult question of coexistence with people.

\section{ACKNOWLEDGEMENTS}

Thank you to members of the Wild Dog Advisory Group who provided wild dog demographic information from reserves. H.D.M. was supported through grants to D.W.M. from Fauna \& Flora International and Siren. Fieldwork was supported by the Endangered Wildlife Trust, De Beers Consolidated Mines and Jaguar Land Rover South Africa. Pat Fletcher provided support and Mariette Wheeler, editorial assistance. Thanks to Markus Gusset and Anthony Maddock for constructive comments on the manuscript.

\section{REFERENCES}

Akçakaya, H.R., Mills, M.G.L. \& Doncaster, C.P. (2007). The role of metapopulations in conservation. In D. Macdonald \& K. Service (Eds), Key topics in conservation biology (pp. 64-84). Oxford, U.K.: Blackwell Publishing.

Bales, S.L., Hellgren, E.C., Leslie Jr, D.M. \& Hemphill Jr, J. (2005). Dynamics of a recolonizing population of black bears in the Ouachita Mountains of Oklahoma. Wildlife Society Bulletin, 33, 1342-1351.

Ballou, J. (1995). An overview of small population biology. Zoo's Print, September 1995, 3-7.

Buettner, U.K., Davies-Mostert, H.T., du Toit, J.T. \& Mills, M.G.L. (2007). Factors affecting juvenile survival in African wild dogs Lycaon pictus in Kruger National Park, South Africa. Journal of Zoology, 272, 10-19. 
Caswell, H. (2001). Matrix population models: construction, analysis and interpretation. Sunderland, M.A.: Sinauer.

Caughley, G. (1994). Directions in conservation biology. Journal of Animal Ecology, 63, 215-244.

Creel, S.R. \& Creel, N.M. (1996). Limitation of African wild dogs by competition with larger carnivores. Conservation Biology, 10, 1-15.

Creel, S.R. \& Creel, N.M. (1998). Six ecological factors that may limit African wild dogs, Lycaon pictus. Animal Conservation, 1, 1-19.

Creel, S.R. \& Creel, N.M. (2002). The African wild dogbehavior, ecology and conservation. Princeton, U.S.A. \& Oxford, U.K.: Princeton University Press.

Creel, S., Mills, M.G.L. \& McNutt, J.W. (2004). Demography and population dynamics of African wild dogs in three critical populations. In D.W. Macdonald \& C. Sillero-Zubiri (Eds), Biology and conservation of wild canids (pp. 337-350). Oxford, U.K.: Oxford University Press.

Davies-Mostert, H.T., Mills, M.G.L. \& Macdonald, D.W. (2009). A critical assessment of South Africa's managed metapopulation recovery strategy for African wild dogs and its value as a template for large carnivore conservation elsewhere. In M. Hayward \& $\mathrm{M}$. Somers (Eds), Reintroduction of top-order predators (pp. 10-42). Oxford, U.K.: Blackwell Publishing.

Davies-Mostert, H.T., Kamler, J.F., Mills, M.G.L., Jackson, C.R., Rasmussen, G.S.A., Groom, R.J. \& Macdonald, D.W. (2012). Long-distance transboundary dispersal of African wild dogs among protected areas in southern Africa. African Journal of Ecology, 50, 500-506.

Davies-Mostert, H.T., Mills, M.G.L. \& Macdonald, D.W. (2013). Hard boundaries influence wild dogs' diet and prey selection. Journal of Applied Ecology, 50, 1358-1366.

Frame, L.H. \& Frame, G.W. (1976). Female wild dogs emigrate. Nature, 263, 227-229.

Fuller, T.K., Kat, P.W., Bulger, J.B., Maddock, A.H., Ginsberg, J.R., Burrows, R., McNutt, J.W. \& Mills, M.G.L. (1992). Population dynamics of African wild dogs. In D.R. McCullough \& H. Barrett (Eds), Wildlife 2001: populations (pp. 1125-1139). London, U.K.: Elsevier Science Publishers.

Ginsberg, J.R., Mace, G.M. \& Albon, S.D. (1995). Local extinction in a small and declining population: wild dogs in the Serengeti. Proceedings of the Royal Society of London B, 262, 221-228.

Ginsberg, J.R. \& Woodroffe, R. (1997). Extinction risks faced by remaining wild dog populations. In $\mathrm{R}$. Woodroffe, J. Ginsberg \& D. Macdonald (Eds), The African wild dog - status survey and conservation action plan (pp. 75-87). Gland, Switzerland: IUCN.

Gusset, M. (2009). A framework for evaluating reintroduction success in carnivores: lessons from African wild dogs. In M. Hayward \& M. Somers (Eds), Reintroduction of top-order predators (pp. 307-320). Oxford, U.K.: Blackwell Publishing.

Gusset, M. (2010). The re-introduction of African wild dogs in South Africa. In P.S. Soorae (Ed.), Global reintroduction perspectives: additional case-studies from around the globe (pp. 220-224). Abu Dhabi: IUCN/SSC Re-introduction Specialist Group.
Gusset, M., Jakoby, O., Müller, M.S., Somers, M.J., Slotow, R. \& Grimm, V. (2009). Dogs on the catwalk: modelling re-introduction and translocation of endangered wild dogs in South Africa. Biological Conservation, 142, 2774-2781.

Gusset, M. \& Macdonald, D.W. (2010). Group size effects in cooperatively breeding African wild dogs. Animal Behaviour, 79, 425-428.

Gusset, M., Ryan, S.J., Hofmeyr, M., Van Dyk, G., Davies-Mostert, H.T., Graf, J.A., Owen, C., Szykman, M., Macdonald, D.W., Monfort, S.L., Wildt, D.E., Maddock, A.H., Mills, M.G.L., Slotow, R. \& Somers, M.J. (2008). Efforts going to the dogs? Evaluating attempts to re-introduce endangered wild dogs in South Africa. Journal of Applied Ecology, 45, 100-108.

Gusset, M., Stewart, G.B., Bowler, D.E. \& Pullin, A.S. (2010). Wild dog reintroductions in South Africa: a systematic review and cross-validation of an endangered species recovery programme. Journal of Nature Conservation, 18, 230-234.

Hofmeyr, M., Bingham, J., Lane, E.P., Ide, A. \& Nel, L. (2000). Rabies in African wild dogs (Lycaon pictus) in the Madikwe Game Reserve, South Africa. Veterinary Record, 146, 50-52.

Hofmeyr, M., Hofmeyr, D., Nel, L. \& Bingham, J. (2004). A second outbreak of rabies in African wild dogs (Lycaon pictus) in Madikwe Game Reserve, South Africa, demonstrating the efficacy of vaccination against natural rabies challenge. Animal Conservation, 7, 193-198.

Hood, G.M. (2006). PopTools version 2.7.5. http://www. cse.csiro.au/poptools.

Hunter, L.T.B, Pretorius, K., Carlisle, L.C., Rickelton, M., Walker, C., Slotow, R. \& Skinner, J.D. (2007). Restoring lions Panthera leo to northern KwaZuluNatal, South Africa: short-term biological and technical success but equivocal long-term conservation. Oryx, 41, 196-204.

Kemp, L. \& Mills, M.G.L. (2005). The 4th wild dog and 2nd cheetah photographic census in Kruger National Park. Skukuza, South Africa: Unpublished report, SANParks.

Lacy, R. (1993). Vortex: a computer simulation model for population viability analysis. Wildlife Research, 20, 45-65.

Lande, R. (1993). Risks of population extinction from demographic and environmental stochasticity and random catastrophes. American Naturalist, 142, 911-927.

Laurenson, M.K., Shiferaw, F. \& Sillero-Zubiri, C. (1997). Disease, domestic dogs and the Ethiopian wolf: the current situation. In C. Sillero-Zubiri \& D.W. Macdonald (Eds), The Ethiopian wolf status survey and conservation action plan (pp. 32-42). Gland, Switzerland: IUCN/SSC Canid Specialist Group.

Levins, R.A. (1969). Some demographic and genetic consequences of environmental heterogeneity for biological control. Bulletin of the Entomological Society of America, 15, 237-240.

Low, A.B. \& Robelo, A.G. (1996). Vegetation of South Africa, Lesotho and Swaziland. Pretoria, South Africa: Department of Environmental Affairs and Tourism. 
Maddock, A.H. (1999). Wild dog demography in Hluhluwe-Umfolozi Park, South Africa. Conservation Biology, 13, 412-417.

Maddock, A.H. \& Mills, M.G.L. (1994). Population characteristics of African wild dogs Lycaon pictus in the Eastern Transvaal Lowveld, South Africa, as revealed through photographic records. Biological Conservation, 76, 57-62.

Maehr, D.S., Land, E.D., Shindle, D.B., Bass, O.L. \& Hoctor, T.S. (2002). Florida panther dispersal and conservation. Biological Conservation, 106, 187-197.

Marino, J., Sillero-Zubiri, C. \& Macdonald, D.W. (2006). Trends, dynamics and resilience of an Ethiopian wolf population. Animal Conservation, 9, 49-58.

Marnewick, K.A., Hayward, M.W., Cilliers, D. \& Somers, M.J. (2009). Survival of cheetahs relocated from ranchland to fenced protected areas in South Africa. In M. Hayward \& M.J. Somers (Eds), The reintroduction of top-order predators (pp. 282-306). Oxford, U.K.: Blackwell Publishing.

McNutt, J.W. (1996). Sex-biased dispersal in African wild dogs, Lycaon pictus. Animal Behaviour, 52, 10671077.

McNutt, J.W. \& Silk, J.B. (2008). Pup production, sex ratios, and survivorship in African wild dogs, Lycaon pictus. Behavioural Ecology and Sociobiology, 62, 1061-1067.

Mills, M.G.L. (1992). A comparison of methods used to study food habits of large African carnivores. In D.R. McCullough \& R.H. Barrett (Eds), Wildlife 2001: populations (pp. 1112-1124). London, U.K.: Elsevier Applied Science.

Mills, M.G.L. \& Biggs, H.C. (1993). Prey apportionment and related ecological relationships between large carnivores in Kruger National Park. Symposia of the Zoological Society of London, 65, 253-268.

Mills, M.G.L., Ellis, S., Woodroffe, R., Maddock, A., Stander, P., Rasmussen, G., Pole, A., Fletcher, P., Bruford, M., Wildt, D., Macdonald, D. \& Seal, U. (1998). Population and habitat viability analysis for the African wild dog Lycaon pictus in southern Africa. Pretoria, South Africa: IUCN/SSC Conservation Breeding Specialist Group Workshop.

Mills, M.G.L. \& Gorman, M.L. (1997). Factors affecting the density and distribution of wild dogs in the Kruger National Park. Conservation Biology, 11, 1397-1406.

Pletscher, D.H., Ream, R.R., Boyd, D.K., Fairchild, M.W. \& Kunkel, K.E. (1997). Population dynamics of a recolonizing wolf population. Journal of Wildlife Management, 61, 459-465.

Rasmussen, G.S.A., Gusset, M., Courchamp, F. \& Macdonald, D.W. (2008). Achilles' heel of sociality revealed by energetic poverty trap in cursorial hunters. American Naturalist, 172, 508-518.

Reed, D.H. \& Hobbs, G.R. (2004). The relationship between population size and temporal variability in population size. Animal Conservation, 7, 1-8.

Reed, D.H., O'Grady, J.J., Ballou, J.D. \& Frankham, R.
(2003). The frequency and severity of catastrophic die-offs in vertebrates. Animal Conservation, 6, 109-114.

Reich, A. (1981). The behaviour and ecology of the African wild dog Lycaon pictus in the Kruger National Park. (Unpublished Ph.D. thesis). Connecticut, U.S.A.: Yale University.

Reid, J.M., Bignal, E.M., Bignal, S., McCracken, D.I. \& Monaghan, P. (2004). Identifying the demographic determinants of population growth rate: a case study of red-billed choughs Pyrrhocorax pyrrhocorax. Journal of Animal Ecology, 73, 777-788.

Rhodes, R. \& Rhodes, G. (2004). Prey selection and use of man-made barriers by African wild dogs while hunting. South African Journal of Wildlife Research, 34, 135-142.

Robson, C. (1994). Experiment, design and statistics in psychology, 3rd edn. Middlesex, England: Penguin Books.

Saleni, P., Gusset, M., Graf, J.A., Szykman, M., Walters, M. \& Somers, M.J. (2007). Refuges in time: temporal avoidance of interference competition in endangered wild dogs Lycaon pictus. Canid News, 10.2.

Scheepers, J.L. \& Venzke, K.A.E. (1995). Attempts to reintroduce African wild dogs Lycaon pictus into Etosha National Park, Namibia. South African Journal of Wildlife Research, 25, 138-140.

Shafer, C.L. (2001). Inter-reserve distance. Biological Conservation, 100, 215-227.

Smallwood, K.S. \& Schonewald, C. (1996). Scaling population density and spatial pattern for terrestrial, mammalian carnivores. Oecologia, 105, 329-335.

Somers, M.J., Graf, J.A., Szykman, M., Slotow, R. \& Gusset, M. (2008). Dynamics of a small re-introduced population of wild dogs over 25 years: Allee effects and the implications of sociality for endangered species' recovery. Oecologia, 158, 239-247.

Somers, M.J., Gusset, M. \& Dalerum, F. (2012). Modelling the effect of fences on the viability of spatially structured populations of African wild dogs. In M.J. Somers \& M.W Hayward (Eds), Fencing for conservation: restriction of evolutionary potential or a riposte to threatening processes? (pp. 187-196). New York, U.S.A.: Springer.

Van Dyk, G. \& Slotow, R. (2003). The effects of fences and lions on the ecology of African wild dogs reintroduced to Pilanesberg National Park, South Africa. African Zoology, 38, 79-94.

White, P.J., Lemke, T.O., Tyers, D.B. \& Fuller, J.A. (2008). Initial effects of reintroduced wolves Canis lupus on bighorn sheep Ovis canadensis dynamics in Yellowstone National Park. Wildlife Biology, 14, 138-146.

Woodroffe, R., Davies-Mostert, H.T., Ginsberg, J., Graf, J., Leigh, K., McCreery, K., Mills, M.G.L., Pole, A., Rasmussen, G., Robbins, R., Somers, M. \& Szykman, M. (2007). Rates and causes of mortality in endangered African wild dogs (Lycaon pictus): lessons for management and monitoring. Oryx, 41, 215-223.

Responsible Editor: M.J. Somers 